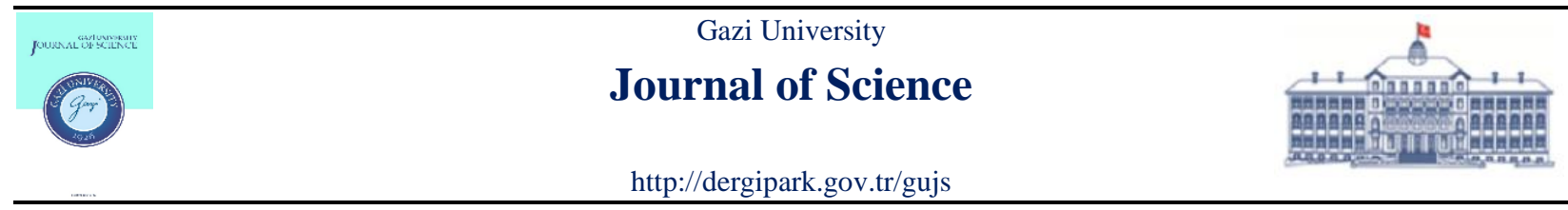

\title{
Design and Implementation of a Simple and Efficient Control Strategy for PVEs
}

\author{
Youssef MALLAL ${ }^{1, *}$, Youssef ALIDRISSI ${ }^{2}$ (D) Lhoussain EL BAHIR $^{1}$ (D) Touria HASSBOUN $^{1}$ (D)
}

\begin{abstract}
${ }^{1}$ Laboratory of Electrical Engineering and Control Systems (LGECOS), National School of Applied Sciences, Cadi Ayyad University, Av. Abdelkrim El Khattabi B.P. 575, 40000, Marrakech, Morocco

${ }^{2}$ Renewable Energies and Materials Laboratory (LERMA), International University of Rabat Technopolis Rabat-Shore Rocade Rabat-Salé, 11103, Rabat, Morocco
\end{abstract}

\section{Highlights}

- This paper presents the design and implementation of a simple and powerful control method for PVEs.

- The manuscript also presents an efficient method to extract the PV model parameters.

- The proposed prototype behaves precisely as the studied solar panel.

\begin{tabular}{l} 
Article Info \\
\hline Received: 22 Feb 2020 \\
Accepted: 19 Oct 2020 \\
Keywords \\
Renewable energy \\
Photovoltaic modeling \\
Photovoltaic emulator \\
Buck converter \\
Control strategy
\end{tabular}

\section{INTRODUCTION}

The companies operating in the PV domain are not always able to ensure the desired test conditions for their developed PV devices such as solar inverters and MPPT controllers. A test platform comprising PV panels is costly and requires controlled temperature and irradiation profiles. Besides, there are expensive grid-connected systems that require being testing before being installed to guarantee proper coordination between energy sources. As a solution, researchers have developed PVEs able to reproduce the same electrical characteristics as the PV panels, regardless of external conditions [1]. The PV emulators designed in the literature are based on several fundamental elements, namely the PV model, the reference generation technique, the feedback control, and the power stage. The PV model replicates the electrical behavior of the reference panel understudy, the reference generation technique determines the operating point of the emulator-load system, and the controller maintains the emulator output current to its reference value. The PV model, the reference generation, and the feedback control can be implemented in analog or digital platforms.

One of the first analog PVEs is proposed in [2]. This PV emulator functions based on amplifying the output current of a single solar cell to emulate the electrical behavior of a PV panel. The temperature level is not directly controlled, and it requires a halogen lamp to simulate the solar radiation. Similar works, using a circuit magnifier of the photodiode I-V characteristic, were presented in [3]. A light-emitting diode 
simulates solar radiation behavior. A temperature controller of the photodiode manages the temperature level. The authors in [4] have emulated the electrical behavior of the PV panel using analog electronic components to implement the PV model and an analog PI controller. The power stage combines a linear voltage regulator and a DC power supply. An amp-ops based PVE was proposed in [5], and it is dedicated to MPPT algorithms testing.

The analog approaches require less calculation time, but they are susceptible to noise and not flexible in considering varying environmental conditions [6]. To deal with the previously mentioned analog device limitations, researchers have developed several prototypes of PV emulators. These PV emulators consist of a power converter and a software part that includes the PV model, reference generation technique, and the feedback control.

Various digital approaches were presented in the literature [7-10]. In [7], the authors used a DSP board to control a buck converter. The Resistance Comparison Method is the reference generation technique adopted. Consisting of a comparison between the resistance of the PV model and the load resistance value, the operating point ensures that both resistances are equal. The implementation on the DSP board could improve the performance of the PV emulator due to its high processing power. However, the design would be more complicated than other boards such as the dSPACE and the microcontrollers.

Authors in [8] used the dSPACE controller board to implement the PV model using a look-up table method. For reference generation, a direct reference approach has been adopted. The latter consists of connecting the output current of the PV model directly to the input of the adopted controller, but is not recommended as it presents oscillations at the output signals of the emulator [6]. Implementation on the dSPACE board is straightforward, which may facilitate the development process, and therefore will increase the development price as the ASPACE board is more expensive than the FPGA, Microcontrollers, and the DSP.

As stated in [9], the selected support is FPAA (Field Programmable Analog Array) and both static and dynamic solar radiation has been emulated. There is no need for numerical interpolation and no storage of large memory data sets; The FPAA offers a simplicity of reconfiguration and programming compared to FPGA or DSP-based implementations, and no DAC or ADC are required. However, it is more complicated than those applications based on microcontrollers. On the other hand, the direct reference method was also used in this approach, which could induce oscillations at the output signals of the emulator [6].

The PVE based on the FPGA is described in [10]. The design approach is based on the Xilinx System Generator and the MATLAB / Simulink software. This may simplify the process of developing FPGA based PV emulators, but it will also increase the total price as the Matlab / Simulink price is expensive compared to the use of VHDL (VHSIC Hardware Description Language) and the C programming language.

In addition to their technological and performance aspects, the existing commercial emulators are still expensive [6] (Elgar ETS60X14C-PVF 6385 \$ to Magna Power TSD50050240 21,000 \$). Therefore, more attention and effort has to be directed towards the cost aspect, but not at the expense of efficiency, simplicity, and robustness. In this paper, we suggest a simple and efficient PVE able to accurately replicate the solar panel behavior in steady and transient states. The control algorithm was implemented on dsPIC30F4011, which is a 16-bits microcontroller that integrates both the control attributes of a microcontroller and the capabilities of a Digital Signal Processor in a single chip. The power stage contains a DC/DC buck converter designed to support all the voltages and currents of the emulated PV panel. Unlike previous works in this domain, a real PV panel is modelled and emulated instead of referring to datasheet curves [11-13]. The innovative proposed system control is based on a Perturb and Observe (P\&O) algorithm combined with an adaptive PI controller. The results show excellent compatibility between the emulator and the panel responses under different operating conditions. The prototype may be used for educational purpose, Maximum Power Point Tracking (MPPT) regulators testing, or in laboratories with a limited budget.

This paper mainly includes five sections. Section 1 has been devoted to introducing the topic under study, while section 2 presents the modelling of the emulated PV panel. Section 3 describes the PV emulator 
design and implementation. Section 4 discusses the results of the real-time application. Finally, some concluding remarks and perspectives are presented in the last section.

\section{PV PANEL MODELING}

The development of a PVE requires proper modelling of the emulated solar panel. A review of the literature reveals that there are several modelling techniques, including the parametric models and the interpolation models. The parametric models are less fast but more accurate in comparison to the interpolation models [14]. They are based on the physical parameters of the PV panel provided in the manufacturer's datasheet values. In contrast, the interpolation models are based on points of the I-V characteristic, such as the current at the Maximum Power Point (MPP), the voltage at the MPP; short-circuit current, open-circuit voltage. For the proposed prototype, the 1D2R parametric model was adopted due to its simplicity and accuracy. Its electrical equivalent circuit (1D2R) is presented in Figure 1.

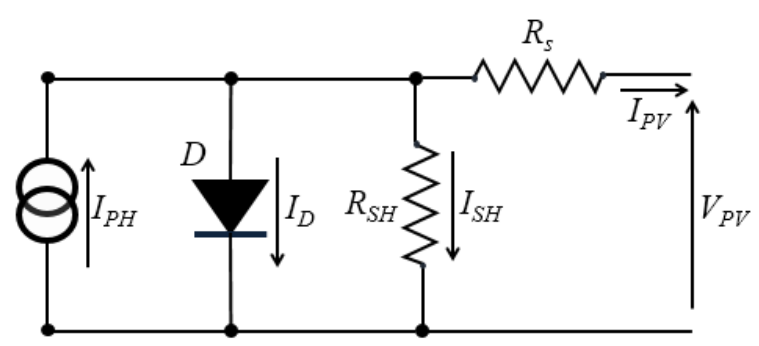

Figure 1. 1D2R electrical equivalent circuit

This equivalent model circuit is produced by subtracting a diode current, taking into account the physical effects at the p-n junction, from a constant current [11]. The current generator describes the photo-induced current. The resistance $\left(\mathrm{R}_{\mathrm{S}}\right)$ models contact and internal cell resistances. The resistance $\left(\mathrm{R}_{\mathrm{SH}}\right)$ takes into account the effect of leakage currents. The model was implemented using the look-up table method to increase the performances of the developed prototype. Instead of the direct calculation method, which requires digital controllers with high processing power. Nothing that the more data stored in the look-up table, the more that model accuracy is increased.

By applying Kirchhoff's laws on the equivalent circuit in Figure 1, the nonlinear I-V characteristic of a PV panel is given by the Equation (1):

$$
I_{P V}=I_{P H}-I_{D}-I_{S H}
$$

$\left(I_{D}\right)$ is the Shockley diode current expressed as follows:

$$
I_{D}=I_{R S}\left[e^{\frac{V}{\alpha V_{t}}}-1\right]
$$

$V_{t}=\frac{k T}{q}:$ The thermal voltage and $(\alpha)$ is the diode ideality factor. Equation (3) may express the diode reverse saturation current $\left(I_{R S}\right)$ :

$$
I_{R S}=I_{0}\left[\frac{T}{T_{r}}\right]^{3} e^{\frac{q E_{g}}{\alpha k}\left(\frac{1}{T_{r}}-\frac{1}{T}\right)}
$$

where:

Boltzmann constant $(k)$

Band gap energy $\left(E_{g}\right)$
$1.38 \mathrm{e}-23 \mathrm{~J} / \mathrm{K}$

$1.12 \mathrm{eV}$ 
Reference temperature $(\mathrm{Tr})$

The electronic charge $(q)$ $25^{\circ} \mathrm{C}$

1.6e-19 C.

The current $\left(I_{0}\right)$ is the diode reverse saturation current at the reference temperature $T r$, and it can be expressed by:

$$
I_{0}=\frac{I_{s c r}}{e^{\frac{V_{O C}}{V_{t} \alpha}}-1} .
$$

The current $\left(I_{P H}\right)$ is the photo-induced current, which is directly proportional to the solar irradiation, and it can be expressed as follows:

$$
I_{P H}=\frac{G}{G_{n}}\left[I_{s c r}+K_{i}\left(T-T_{r}\right)\right]
$$

$\left(I_{s c r}\right)$ is the short circuit current, $\left(G_{n}\right)$ is the nominal irradiation, and $\left(K_{i}\right)$ is the short circuit currenttemperature coefficient.

By replacing $\left(I_{D}\right)$ and $\left(I_{P H}\right)$ by their values in the Equation (1), the non-linear PV characteristic can be described as follows:

$$
I_{P V}=I_{P H}-I_{0}\left[e^{\frac{V_{P V}+I_{P V} R_{S}}{V_{t} \alpha}}-1\right]-\frac{V_{P V}+R_{S} I_{P V}}{R_{S H}} .
$$

As shown in Equation (6), the series resistance $R s$ and the parallel resistance $R_{S H}$ should be estimated to identify the current-voltage characteristic of the emulated PV panel. For this reason, The Equation (6) is applied at the maximum power point $\left(V_{M P}, I_{M P}\right)$ given in the datasheet:

$$
\begin{aligned}
I_{M P}=I_{P H}-I_{0} & {\left[e^{\frac{V_{M P}+I_{M P} R_{S}}{V_{t} \alpha}}-1\right] } \\
& -\frac{V_{M P}+R_{S} I_{M P}}{R_{S H}} .
\end{aligned}
$$

The values of the series resistance $\left(R_{S}\right)$ and the parallel resistance $R_{S H}$ could be estimated, by defining the following optimization criteria $(\beta)$ :

$$
\begin{gathered}
\beta=\left[I_{M P}-I_{P H}+I_{0}\left[e^{\frac{V_{M P}+I_{M P} R_{S}}{V_{t} \alpha}}-1\right]\right. \\
\left.+\frac{V_{M P}+R_{S} I_{M P}}{R_{S H}}\right]^{2} .
\end{gathered}
$$

The PV module used in this study is the SR-20 PV panel. In order to model this panel, all model parameters are identified on the basis of the technical details provided by the manufacturer in the Standard Test Conditions (STCs) using the equations mentioned above. The technical characteristics of the SR-20 panel could be found in [15]. The adjusted series $\left(R_{\mathrm{s}}\right)$ and shunt resistance $\left(\mathrm{R}_{\mathrm{SH}}\right)$ are $4 \mathrm{~m} \Omega$ and $1 \mathrm{k} \Omega$, respectively. 

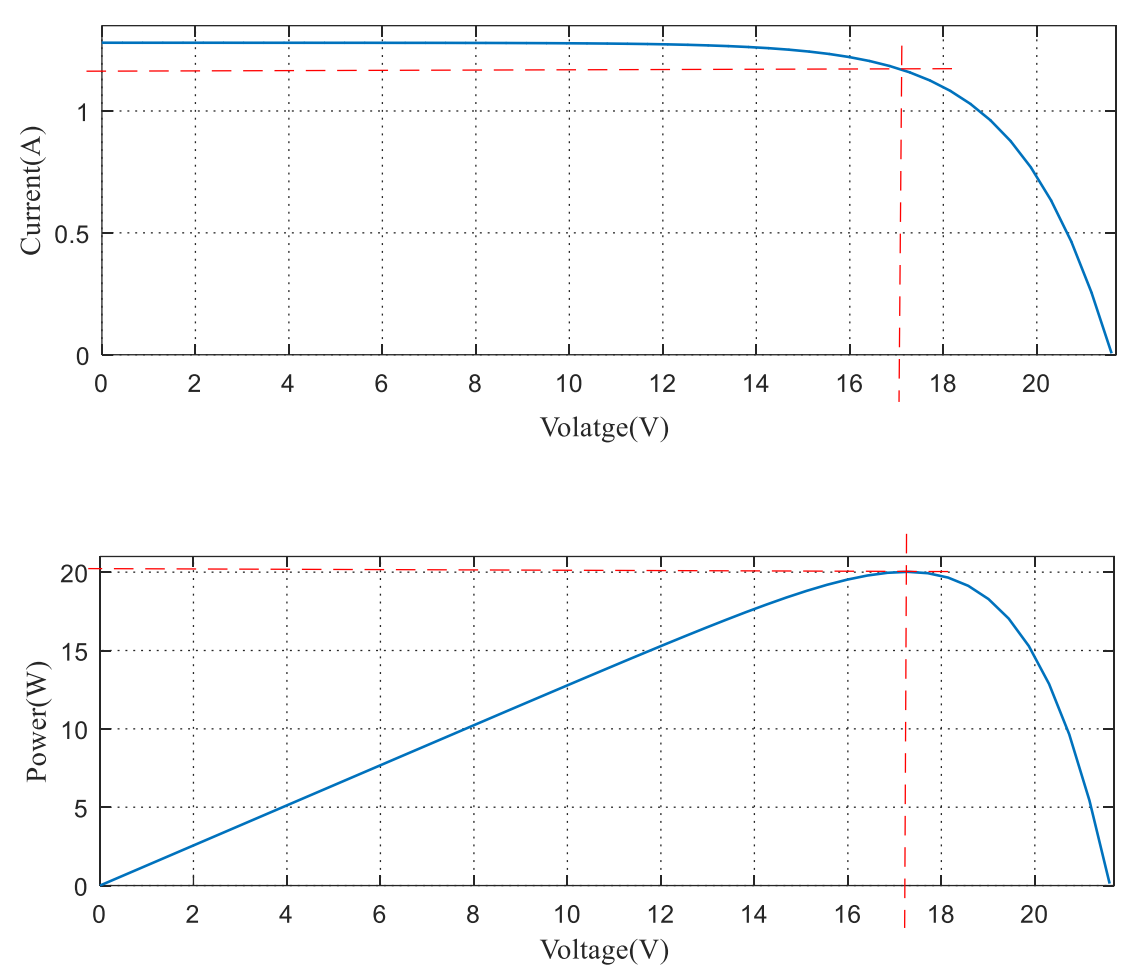

Figure 2. Simulated current-voltage and power-voltage characteristics of the adjusted model at the standard test conditions $\left(G=1000 \mathrm{~W} / \mathrm{m}^{2}, T=25^{\circ} \mathrm{C}\right)$

Before loading the PV model on the dsPIC device, as a lookup table, it must be validated to ensure that it behaves identically as the SR-20 panel. For this reason, the model was validated in simulation by comparing the obtained characteristic with the datasheet values in Table 1 and in real-time by comparing the SR-20 panel output current with the adjusted model output current, under natural weather conditions.

As illustrated in Figure 2, the PV model can generate the $\mathrm{I}-\mathrm{V}$ characteristic points indicated in the datasheet: $\mathrm{V}_{\mathrm{MP}}(17.2 \mathrm{~V}), \mathrm{I}_{\mathrm{MP}}(1.17 \mathrm{~A}), \mathrm{I}_{\mathrm{SC}}(1.28 \mathrm{~A}), \mathrm{V}_{\mathrm{OC}}(21.6 \mathrm{~V})$, and $\mathrm{P}_{\mathrm{MP}}(20 \mathrm{~W})$ at $\mathrm{STCs}\left(\mathrm{G}=1000 \mathrm{~W} / \mathrm{m}^{2}, \mathrm{~T}=25^{\circ} \mathrm{C}\right)$. The electrical behavior of the model is precisely similar to that of a PV panel.

The model is also validated in real weather conditions. A CM10 Pyranometer and a Pt1000 sensor respectively measured solar radiation and temperature. The results of real-time validation are shown in Figure 3. The solar irradiation varied between $220 \mathrm{~W} / \mathrm{m}^{2}$ and $630 \mathrm{~W} / \mathrm{m}^{2}$. The temperature has changed between $14^{\circ} \mathrm{C}$ and $17^{\circ} \mathrm{C}$ ); these variations are due to cloudy periods. The results show that the model correctly behaves as the studied SR-20 panel, Figure 3. 


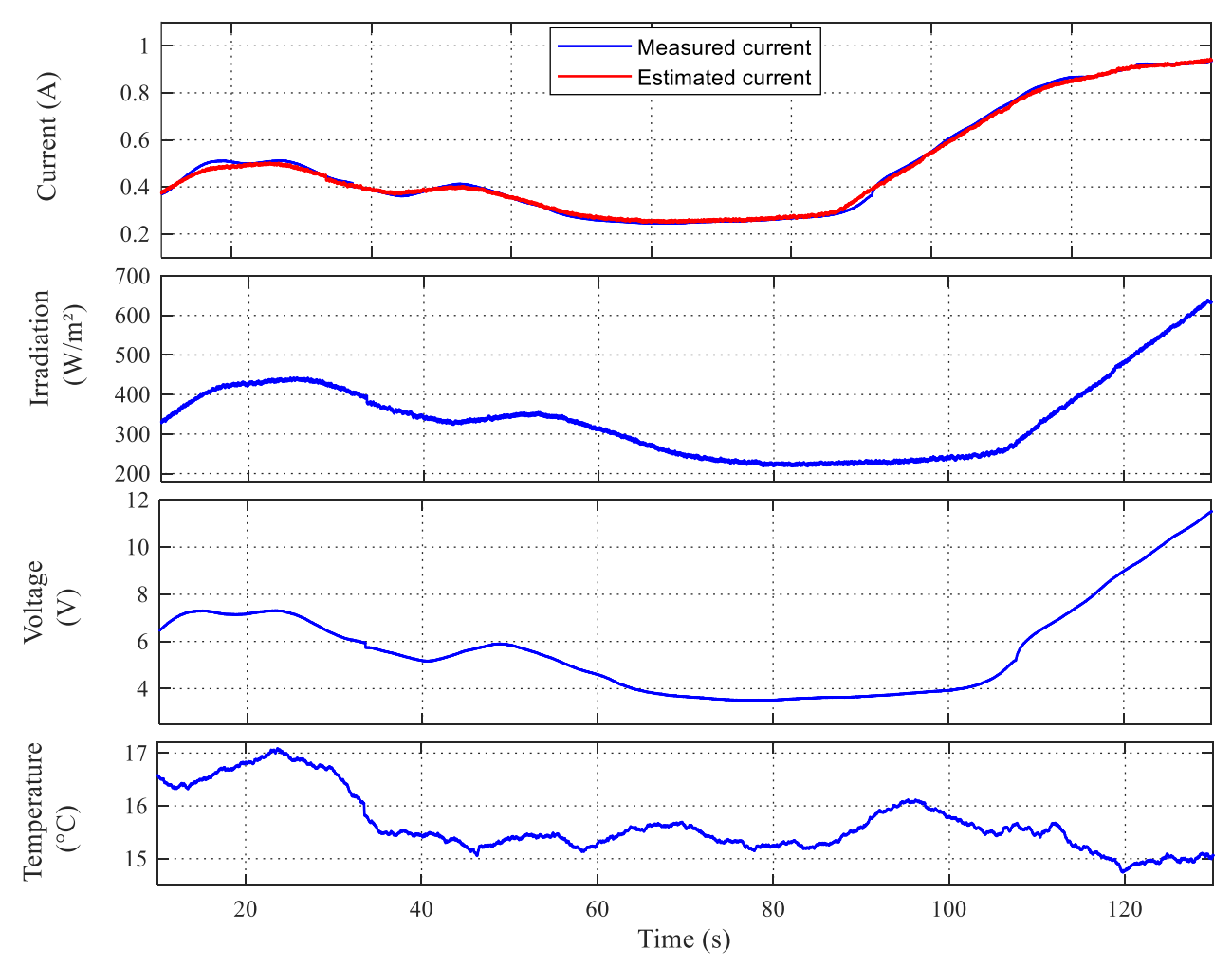

Figure 3. PV Model validation under real weather conditions

\section{SYSTEM DESIGN AND CONTROL}

A detailed synoptic diagram of the proposed emulator is shown in Figure 4 to simplify the comprehension of the adopted architecture. The hardware structure of the proposed emulator is given in Figure 5. The dsPIC4011 is chosen as a digital controller due to its affordable price and its processing power (30 MIPS using an internal oscillator), which makes the developed prototype low cost (150\$) compared with the existing commercial PVEs [6] (Elgar ETS60X14C-PVF 6385 \$ to Magna Power TSD50050240 21,000 \$). At the same time, it benefits from the processing power of the dsPIC device, which combines between the control attributes of a microcontroller and the capabilities of the DSP engine.

The user defines the desired temperature $T$ and solar radiation $G$ signals as PV model inputs to generate the corresponding current $I_{P V}$ to feed in the reference generation block. Depending on the algorithm implemented in the latter, the operating point of the Emulator-Load system is determined by generating a current reference Iref. The emulator output current $I_{P V E}$ is maintained to its reference value Iref via the controller.

The model and control the algorithm are programmed under MPLAB X IDE and loaded as a HEX file on the memory program of the dsPIC30F4011, using PICkit3 application. The LEM LV20-P and the LEM LA55-P are respectively the current and voltage sensors. Their outputs are connected to a conditioner circuit to deliver a voltage between 0 to \pm 5 volts, adapted as an input of the dsPIC device ADC.

During the development of the proposed emulator, the primary considered elements are: (a) the design of a PVE with a static and dynamic to behavior similar a real PV panel. (b) An accurate and straightforward control algorithm easy to be programmed in low-cost digital platforms. The implementation and design of each block in the proposed architecture are detailed in the following subsections. 


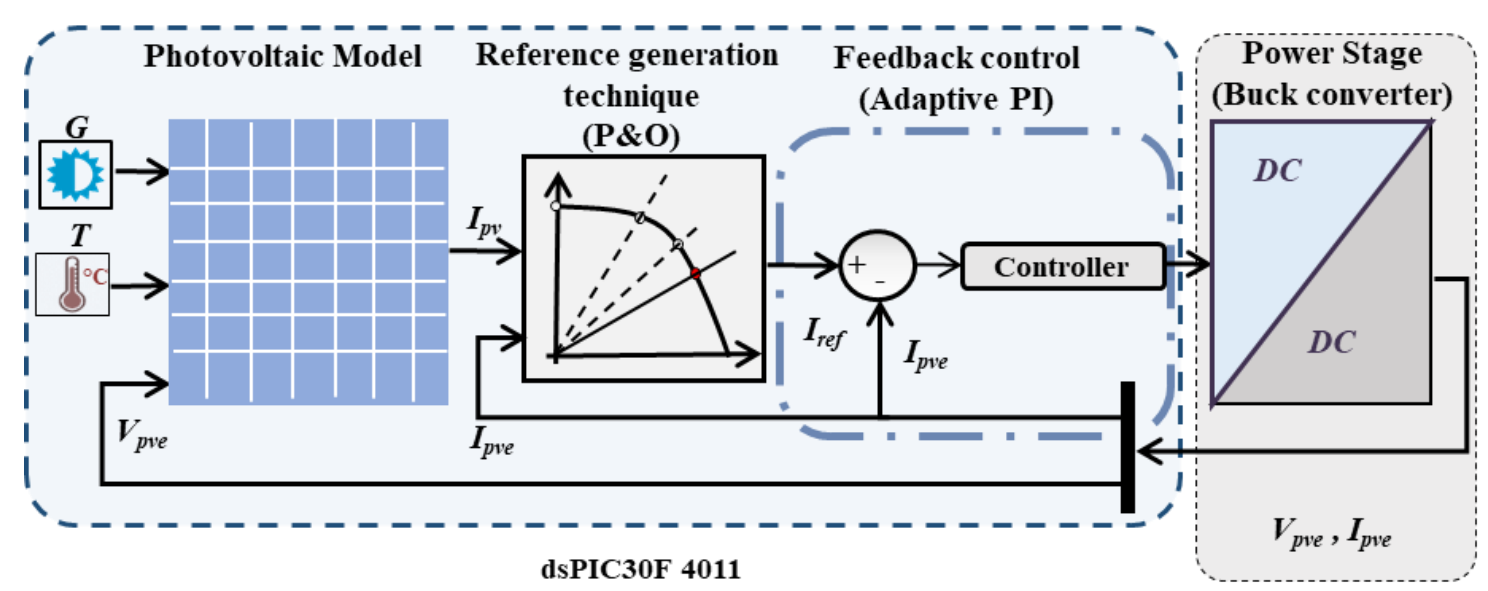

Figure 4. Detailed synoptic diagram of the proposed photovoltaic emulator

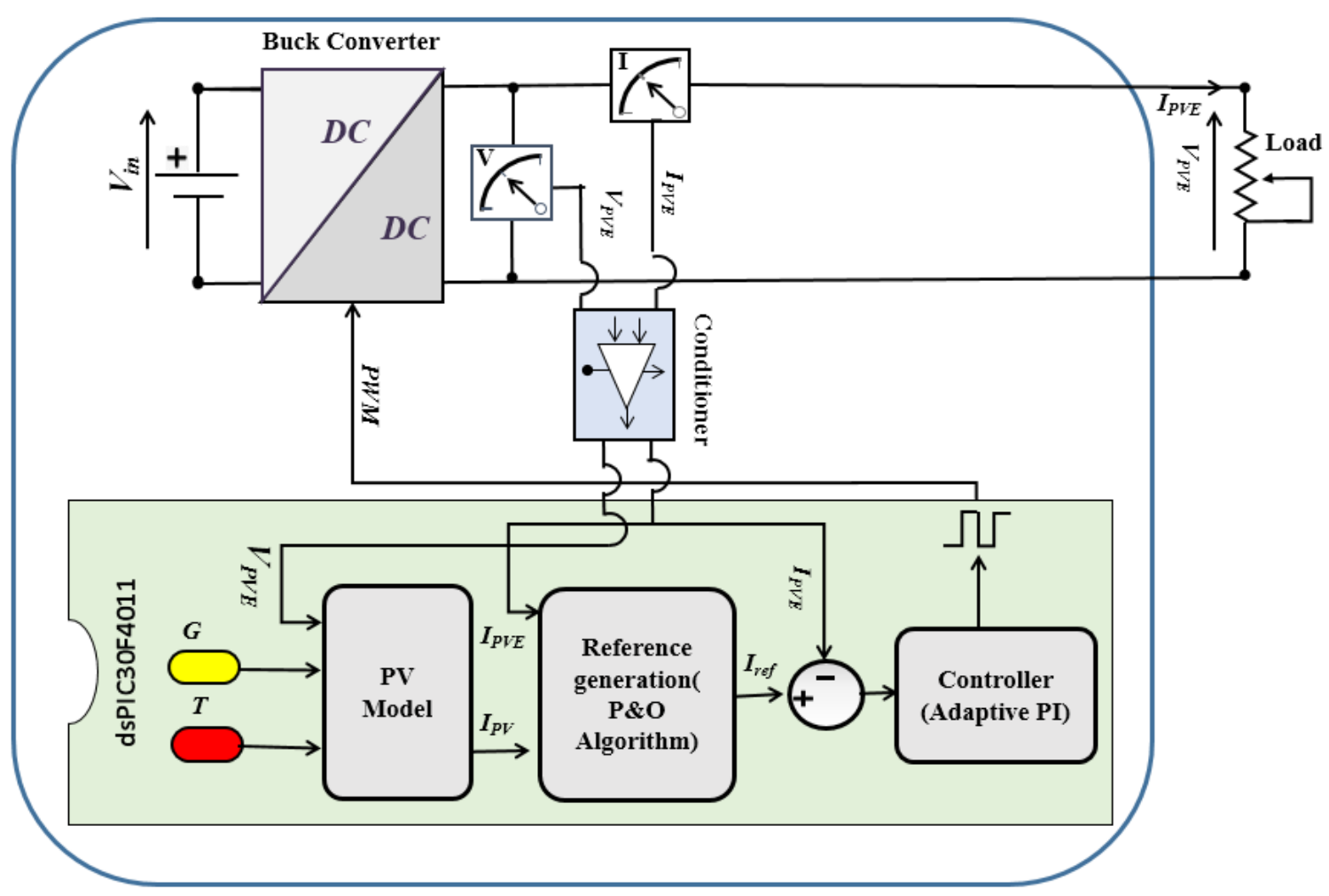

Figure 5. Hardware structure of the proposed emulator 


\subsection{Reference Generation Technique}

The system described in Figure 4 behaves as a PVE if its operating point is the intersection between the load and PV model I-V characteristics. Equation (9) characterizes the intersection point

$$
R_{P V}=R_{\text {Load }}
$$

where:

$$
\left\{\begin{array}{c}
\frac{V_{P V}}{I_{P V}}=R_{P V} \\
\frac{V_{P V E}}{I_{P V E}}=R_{\text {Load. }} .
\end{array}\right.
$$

To ensure the equality of Equation (9), there are various reference generation techniques reported in the literature. In [16], a Hill-Climbing based reference generation was developed. The latter functions without a need for an additional controller. A direct referencing method was presented in [17]; it consists of considering the output current of the PV model as the set-point of the controller. The output voltage of the buck converter is considered as the input voltage of the PV model.

The techniques mentioned above are both simple, but they present oscillations at the emulator output signals [6]. As a solution, a $\mathrm{P} \& \mathrm{O}$ algorithm was used to produce a more stable emulator output. The operation principle is illustrated in Figure 6, if the system begins with an operating point (A). Where $R_{P V}(A)<R_{\text {Load }}$, The reference generation block decreases the current IPV to bring the system at the point $\mathrm{B}$, where $R_{P V}(B)=R_{\text {Load }}$. The same block increases the current $\mathrm{I}_{\mathrm{PV}}$ if the system starts at point $\mathrm{C}$, where $R_{P V}(C)>R_{\text {Load }}$.

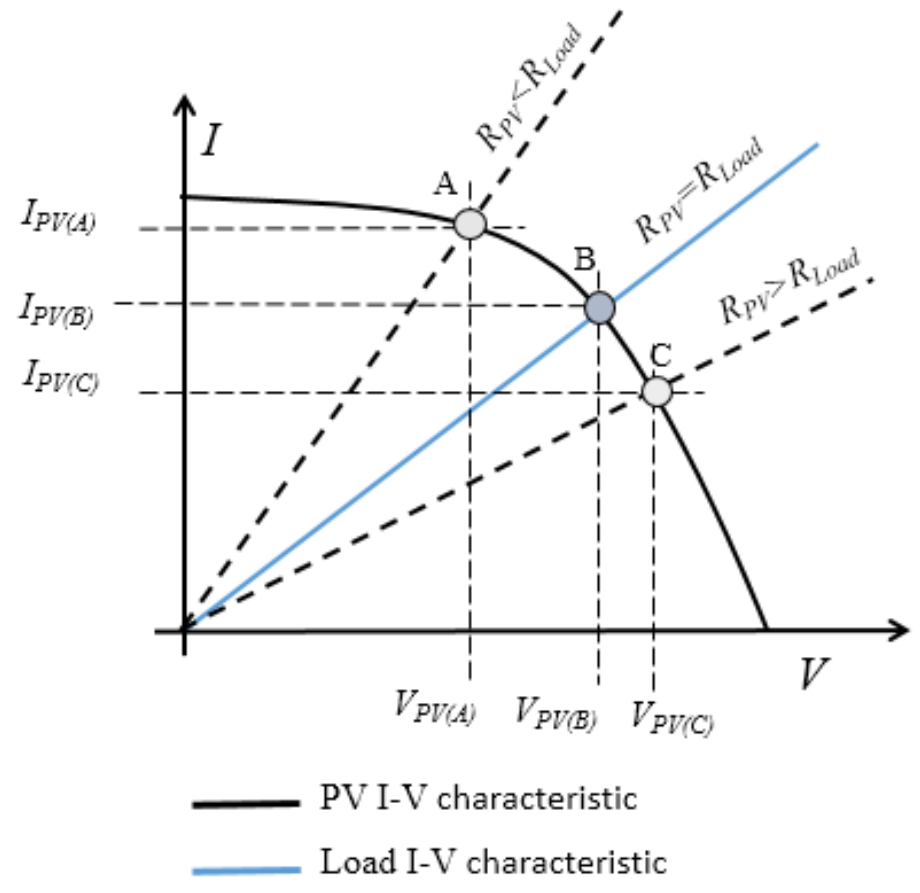

Figure 4. Reference generation principle

The P\&O method consists of comparing the $I_{P V}$ with $I_{P V E}$. If $I_{P V}$ is larger than $I_{P V E}$, the reference current, Iref, is decreased by subtracting the current step, $\Delta I$, from $I_{P V}$, while if $I_{P V}$ is smaller than $I_{\mathrm{PVE}}$, Iref is increased by adding $\Delta I$ to $I_{P V}$ values, Figure 7 . This process is simple and is directly programmable on any digital platform. 


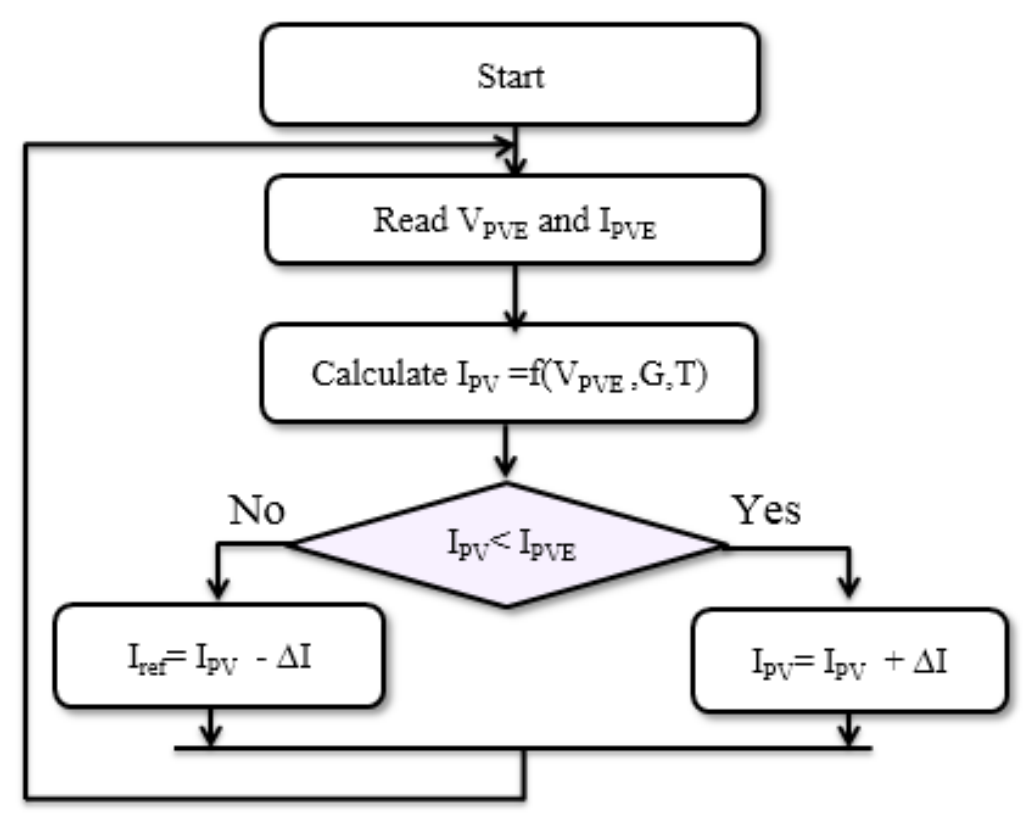

Figure 5. Flowchart of the reference generation technique

\subsection{Dc/dc Buck Converter Design}

There are many adopted topologies, such as the linear regulator, Switching-Mode Power Supply (SMPS), DC power supply with a variable resistor, and programmable DC power supply. The linear regulators are simple and less noisy, but they are inefficient and dedicated to low powered devices. The programmable DC power supply integrates the feedback control and experiences a response delay limitation. Since the SMPS offers high efficiency and a wide input range, it is commonly used for the PV emulator applications. There are various types of SMPS, namely the buck converter, half and full-bridge dc-dc converter, the Buck-Boost converter, LLC resonant dc-dc converter [18].

For the developed prototype, a Buck converter was adopted to cover the I-V characteristic. The electrical circuit of the buck converter is illustrated in Figure 8. The latter operates in continuous conduction mode (CCM).

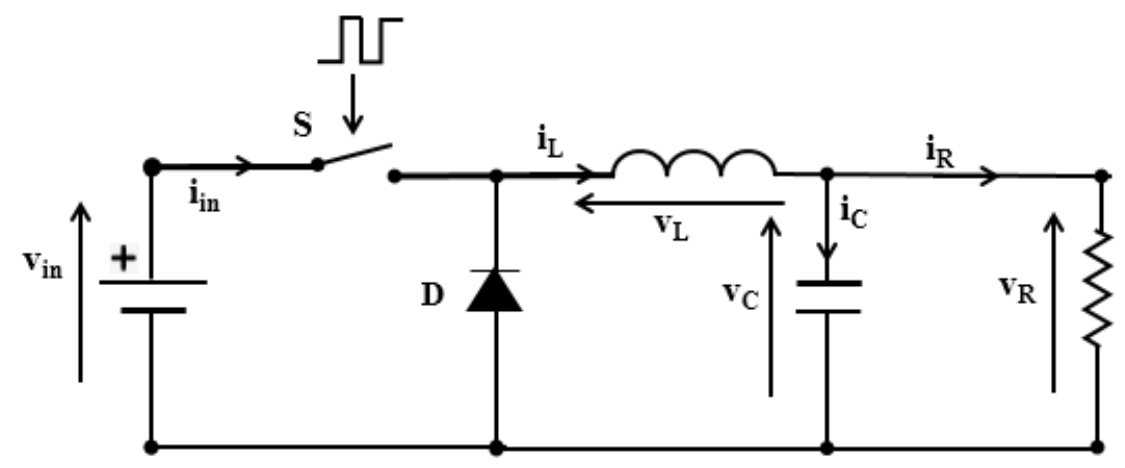

Figure 6. The electrical circuit of the buck converter

The calculation of the inductor (L) and the capacitor (C) values are based on the Equations (11) and (12), obtained by studying the operation modes of Buck converter. The specifications of the buck converter are given in Table 1.

$$
L_{\min } \geq \frac{V_{\text {in }}}{4 f_{P W M} \Delta I_{\max }}
$$




$$
C_{\min } \geq \frac{\Delta I_{\max }}{8 f_{P W M} \Delta V_{\max }}
$$

where $\left(\Delta I_{\max }\right)$ is the maximum inductor current ripple, $(\Delta V)$ is the maximum output voltage ripple, $\left(V_{I N}\right)$ is the input voltage, and $f_{P W M}$ is the PWM signal frequency. The DC-DC Buck converter was built using a FOD3120 gate driver connected to an IRF540NPBF MOSFET and UFT800DB8 diode. The selected values of the capacitor and the inductor are $20 \mu \mathrm{F}$ and $0.7 \mathrm{mH}$, respectively.

Table 1. Buck converter design specifications

\begin{tabular}{cc} 
Maximum output voltage ripple $\left(\Delta V_{\max }\right)$ & $50 \mathrm{mV}$ \\
Maximum inductor current ripple $\left(\Delta I_{\max }\right)$ & $30 \%$ \\
Input voltage $\left(V_{I N}\right)$ & $24 \mathrm{~V}$ \\
PWM signal frequency $\left(f_{P W M}\right)$ & $100 \mathrm{kHz}$ \\
\hline
\end{tabular}

\section{- Oscillator and device clocking}

The dsPIC30F4011 offers multiple internal and external clock sources. In this paper, the Internal Fast RC Oscillator $(7.37 \mathrm{MHz})$ was used to eliminate the need for an external clock source. The latter is multiplied by a PLL16 to achieve a high frequency and enhance the performances of the developed emulator. The internal instruction cycle clock $\left(F_{C Y}\right)$ in terms of the system clock source $\left(F_{O S C}\right)$ can be expressed as follows $[19,20]$ :

$$
\begin{aligned}
& F_{C Y}=\frac{F_{O S C}}{4} \\
& =\frac{\text { Source Oscillator Frequency } \times \text { PLL Multiplier }}{\text { Programmable postscalar } \times 4} .
\end{aligned}
$$

For the proposed prototype, the internal instruction cycle clock can be calculated as follows:

$$
\left\{\begin{array}{c}
F_{C Y}=\frac{F_{O S C}}{4}=\frac{7.37 \times 16}{1 \times 4}=30 \mathrm{MHz} \\
F_{C Y}=\frac{1}{M I P S}
\end{array}\right.
$$

with the mentioned above configuration, the maximum speed of the dsPIC30F4011 using an internal oscillator is achieved (30MIPS).

\section{- PWM configuration}

The PWM module in dsPIC30F4011 is designed to generate multiple synchronized PWM signals. Indeed, the dsPIC30F4011 offers 3 PWM generators; each one of them has two PWM output pins that can be generated in normal or complimentary mode. The register that controls the period of the PWM signal is PTPER $[18,19]$; its value can be determined using the Equation (15)

$$
P T P E R=\frac{F_{C Y}}{f_{P W M} \times P T M R_{\text {Prescalar }} \times 2}-1 .
$$

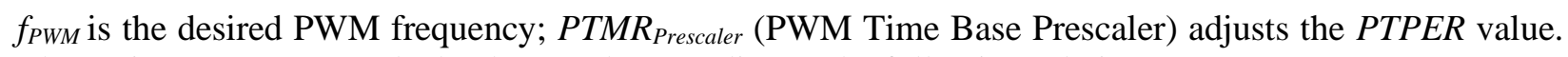
The register $P D C x$ controls the duty cycle according to the following relation: 


$$
P D C x=2 \times d \times P T P E R
$$

with $d$ the desired duty cycle $0<d<1$. For the developed emulator, the buck converter is controlled with a frequency of $100 \mathrm{kHz}$. The value of PTPER is calculated as follows:

$$
\text { PTPER }=\frac{30 \times 10^{6}}{100 \times 10^{3} \times 1}-1=299 .
$$

\subsection{Controller Design and Validation}

By applying Kirchhoff's laws during the ON and the OFF time of the switch $\mathrm{S}$ shown in Figure 8, the following equations could be obtained:

During the ON time of the switch S:

$$
\left\{\begin{array}{l}
\frac{d i_{L}}{d t}=\frac{v_{i n}}{L}-\frac{v_{c}}{L} \\
\frac{d v_{C}}{d t}=\frac{i_{L}}{C}-\frac{v_{C}}{R C}
\end{array}\right.
$$

During the OFF time of the switch S:

$$
\left\{\begin{array}{c}
\frac{d i_{L}}{d t}=-\frac{v_{c}}{L} \\
\frac{d v_{C}}{d t}=\frac{i_{L}}{C}-\frac{v_{c}}{R C}
\end{array} .\right.
$$

The state space representations of the above equations during OFF and $\mathrm{ON}$ time are given by:

During the ON time of the switch S:

$$
\left\{\begin{array}{c}
\dot{x}=A_{1} x+B_{1} v_{i n} \\
y=C_{1} x
\end{array}\right.
$$

with $A_{1}=\left[\begin{array}{cc}0 & -\frac{1}{L} \\ \frac{1}{C} & -\frac{1}{R C}\end{array}\right] ; \quad B_{1}=\left[\begin{array}{c}\frac{1}{L} \\ 0\end{array}\right] ; \quad$ and $\quad C_{1}=\left[\begin{array}{ll}0 & 1\end{array}\right]$.

During the OFF time of the switch S:

$$
\left\{\begin{array}{c}
\dot{x}=A_{2} x+B_{2} v_{i n} \\
y=C_{2} x
\end{array}\right.
$$

with $A_{2}=\left[\begin{array}{cc}0 & -\frac{1}{L} \\ \frac{1}{C} & -\frac{1}{R C}\end{array}\right] ; \quad B_{2}=\left[\begin{array}{l}0 \\ 0\end{array}\right] ; \quad$ and $\quad C_{2}=\left[\begin{array}{ll}0 & 1\end{array}\right]$. 
The average state space model is given by:

$$
\left\{\begin{array}{c}
\dot{x}=A x+B v_{\text {in }} \\
y=C x
\end{array}\right.
$$

$$
\begin{aligned}
& A=A_{1} d+A_{2}(1-d) \\
& B=B_{1} d+B_{2}(1-d) \\
& C=C_{1} d+C_{2}(1-d)
\end{aligned}
$$

where $\mathrm{d}$ is the dutty cycle.

Replacing A, B, and C by their values in Equation (22), gives the following state space representation:

$$
\left[\begin{array}{c}
\frac{d i_{L}}{d t} \\
\frac{d v_{C}}{d t}
\end{array}\right]=\left[\begin{array}{cc}
0 & -\frac{1}{L} \\
\frac{1}{C} & -\frac{1}{R C}
\end{array}\right]\left[\begin{array}{l}
i_{L} \\
v_{C}
\end{array}\right]+\left[\begin{array}{l}
\mathrm{d} \\
L \\
0
\end{array}\right] v_{i n}
$$

By applying the following perturbation around the operating point:

$$
i_{L}=I_{L}+\widehat{\iota_{L}} ; \quad d=D+\hat{d} \quad \text { and } \quad v_{c}=V+\widehat{v}_{c} .
$$

The state-space representation of buck converter derived from the averaged small signals analysis may be expressed as follows:

$$
\left[\begin{array}{c}
\frac{d \hat{\imath}_{L}}{d t} \\
\frac{d \hat{v}_{C}}{d t}
\end{array}\right]=\left[\begin{array}{cc}
0 & -\frac{1}{L} \\
\frac{1}{C} & -\frac{1}{R C}
\end{array}\right]\left[\begin{array}{c}
\hat{\imath}_{L} \\
\hat{v}_{C}
\end{array}\right]+\left[\begin{array}{c}
\frac{V}{L} \\
0
\end{array}\right] \hat{d}
$$

By applying the LT (Laplace Transform) in the system, we obtain:

$$
\left\{\begin{array}{l}
s \hat{l}_{L}=-\frac{1}{L} \hat{v}_{C}+\frac{V}{L} \hat{d} \\
s \hat{v}_{C}=\frac{1}{C} \hat{\imath}_{L}-\frac{1}{R C} \hat{v}_{C} .
\end{array}\right.
$$

The development of these two previous equations gives the following results:

$$
\left\{\begin{array}{l}
G_{v}(s)=\frac{\hat{v}_{p v e}(s)}{\hat{d}(s)}=\frac{V_{i n}}{L C s^{2}+\frac{L}{R} s+1} \\
G_{i}(s)=\frac{\hat{l}_{p v e}(s)}{\hat{d}(s)}=\frac{\frac{V_{i n}}{R}}{L C s^{2}+\frac{L}{R} s+1}
\end{array}\right.
$$


As shown in Figure 5, the designed Buck converter is current controlled, the second transfer function is adopted to identify the adaptive PI parameters:

$$
G_{i}(s)=\frac{\hat{l}_{p v e}(s)}{\hat{d}(s)}=\frac{\frac{V_{i n}}{R}}{L C s^{2}+\frac{L}{R} s+1} .
$$

The second-order term coefficient, LC, could be neglected (LC 1e-7) compared to L/R (L/R 1e-3). The system can then be considered as a first-order system, Equation (28)

$$
G_{i}(s)=\frac{\hat{\imath}_{p v e}(s)}{\hat{d}(s)}=\frac{\frac{V_{\text {in }}}{R}}{\frac{L}{R} s+1} .
$$

The PI parameters are adjusted to guarantee stability, fast response, and a minimal error. The considered PI transfer function is given by:

$$
G_{P I}(s)=\frac{K_{P} s+K_{I}}{s}
$$

Let:

$$
\left\{\begin{array}{c}
\mu_{d}=\frac{R}{K_{I} V_{I N}} \\
\frac{K_{P}}{K_{I}}=\frac{L}{R}
\end{array}\right.
$$

The closed-loop transfer function is reduced to:

$$
G_{C l}=\frac{1}{\mu_{d} s+1}
$$

The obtained values of $\left(K_{P}\right)$ and $\left(K_{I}\right)$ are given by:

$$
\left\{\begin{array}{l}
K_{P}=\frac{L}{\mu_{d} V_{I N}} \\
K_{I}=\frac{R}{\mu_{d} V_{I N}}
\end{array}\right.
$$

where $\left(\mu_{d}\right)$ is the desired system closed-loop constant time. The chosen value for $\mu_{d}$ is $25 \mathrm{~ms}$. The obtained values of $k p$ and $k i$ for the designed adaptive controller are respectively:

$$
\left\{\begin{array}{c}
K_{P}=0.0196 \\
K_{I}=\frac{R}{0.6}
\end{array}\right.
$$

To evaluate the performance of the designed regulator. Two test scenarios were carried out. The first test was performed using three fixed loads with transient variations in reference current, and the second consists in fixing the current at a given value and performing transient variations in the load via controlled relays. The validation of the proposed controller under the transient variations in reference current is illustrated in Figure 9. Three current levels were used $(0.8 \mathrm{~A}, 0.9 \mathrm{~A}, 1 \mathrm{~A})$. The passage from one current value to another takes place suddenly by an external source connected to the dsPIC ADC. As illustrated in the same figure, the difference between the reference current and the current at the converter output is negligible. A zoom of the controller response when passing from $0.9 \mathrm{~A}$ to $1 \mathrm{~A}$ is given in the same figure; The controller response time is faster compared to cloudy passage. 


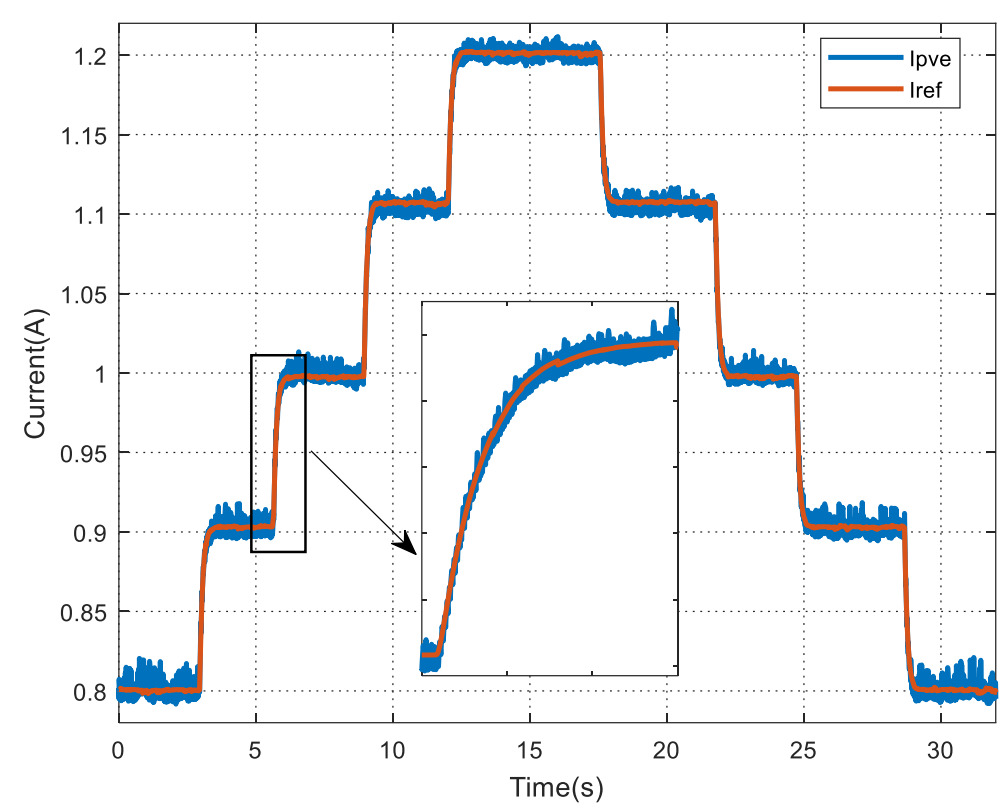

Figure 9. Controller response under abrupt changes of the reference current

The validation of the designed controller, for the transient variations of the load, is illustrated in Figure 10 . Three load values were used $(5 \Omega, 10 \Omega, 15 \Omega)$. The passage from a value of load to another is carried out suddenly via controlled relays. As it is illustrated in the same figure, the current at the output of the converter $I_{P V E}$ is equal to the current reference Iref (1A), even during the abrupt variations of load. A minimal static error (about $0.002 \mathrm{~A}$ ) may appear due to noise related to the sensors and the reading errors of the ADC.
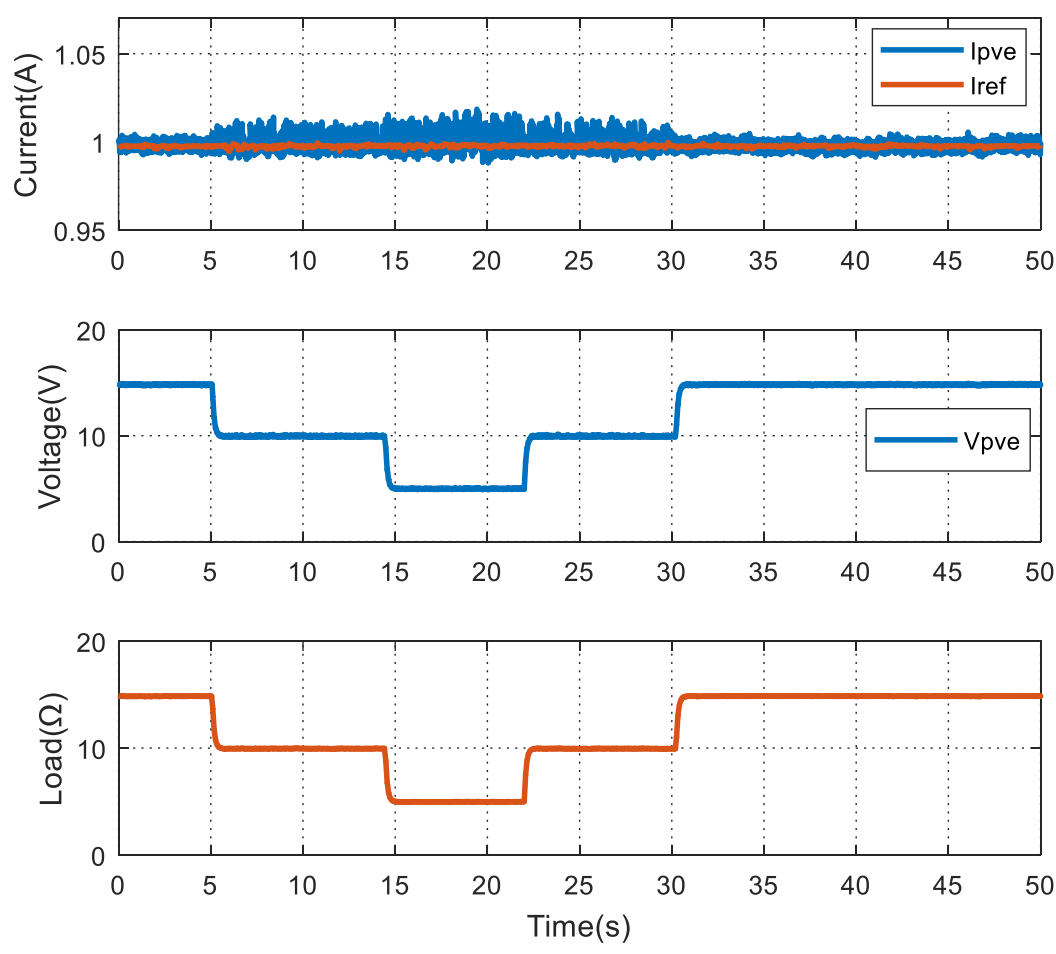

Figure 10. Controller performance analysis under transient load variations 


\section{EXPERIMENTAL RESULTS}

An experimental setup was designed to evaluate the performance of the developed emulator. Figure 11 presents the validation scheme. The dsPIC based PV emulator was connected to a variable load. The sensors' signals are adapted to the ADC inputs of the dSPACE controller board using a conditioner circuit.

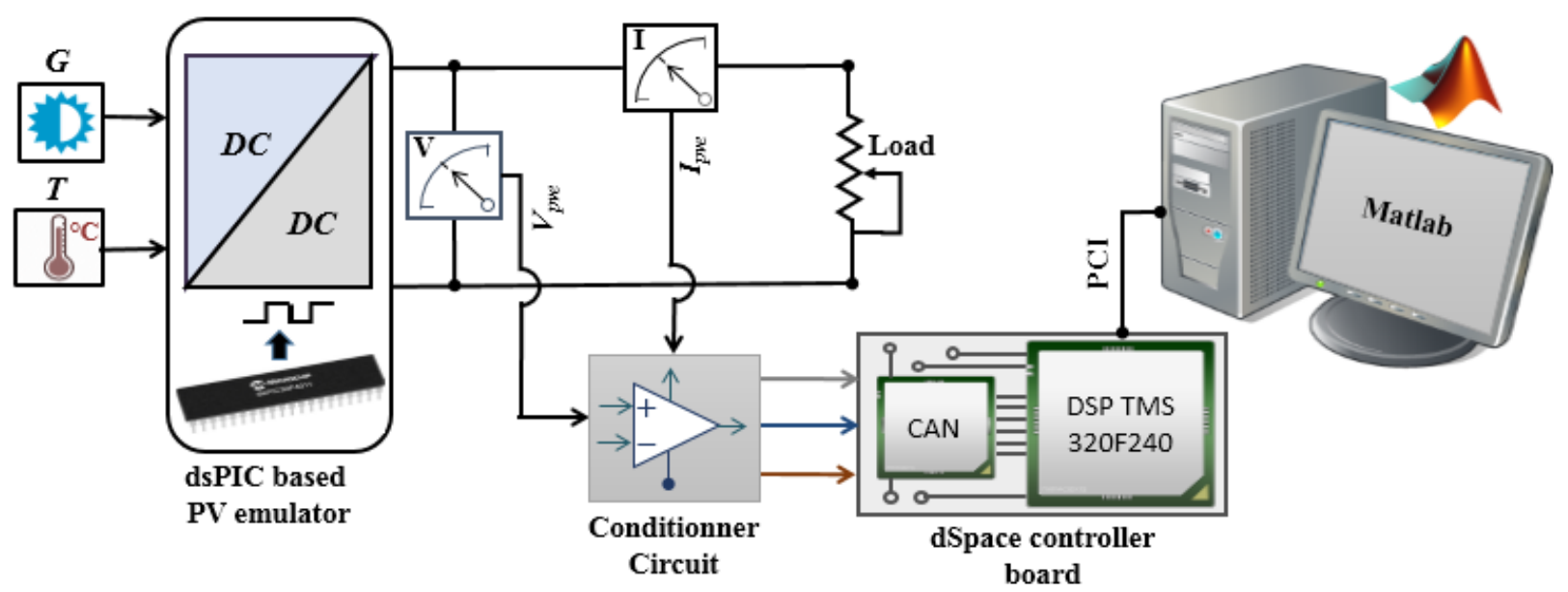

Figure 11. Validation technique

Figure 12 illustrates the key elements of the experimental test setup. The LEM LA55-P and the LEM LV20$P$ respectively measure the current and voltage. The PICKIT3 programmer is used to load the program Hex file into the memory program of the dsPIC device. Data acquisition was carried out under ControlDesk software combined with Matlab/Simulink. The PVE was tested in a steady state and dynamic state under transient variations of solar radiation, temperature, and load.

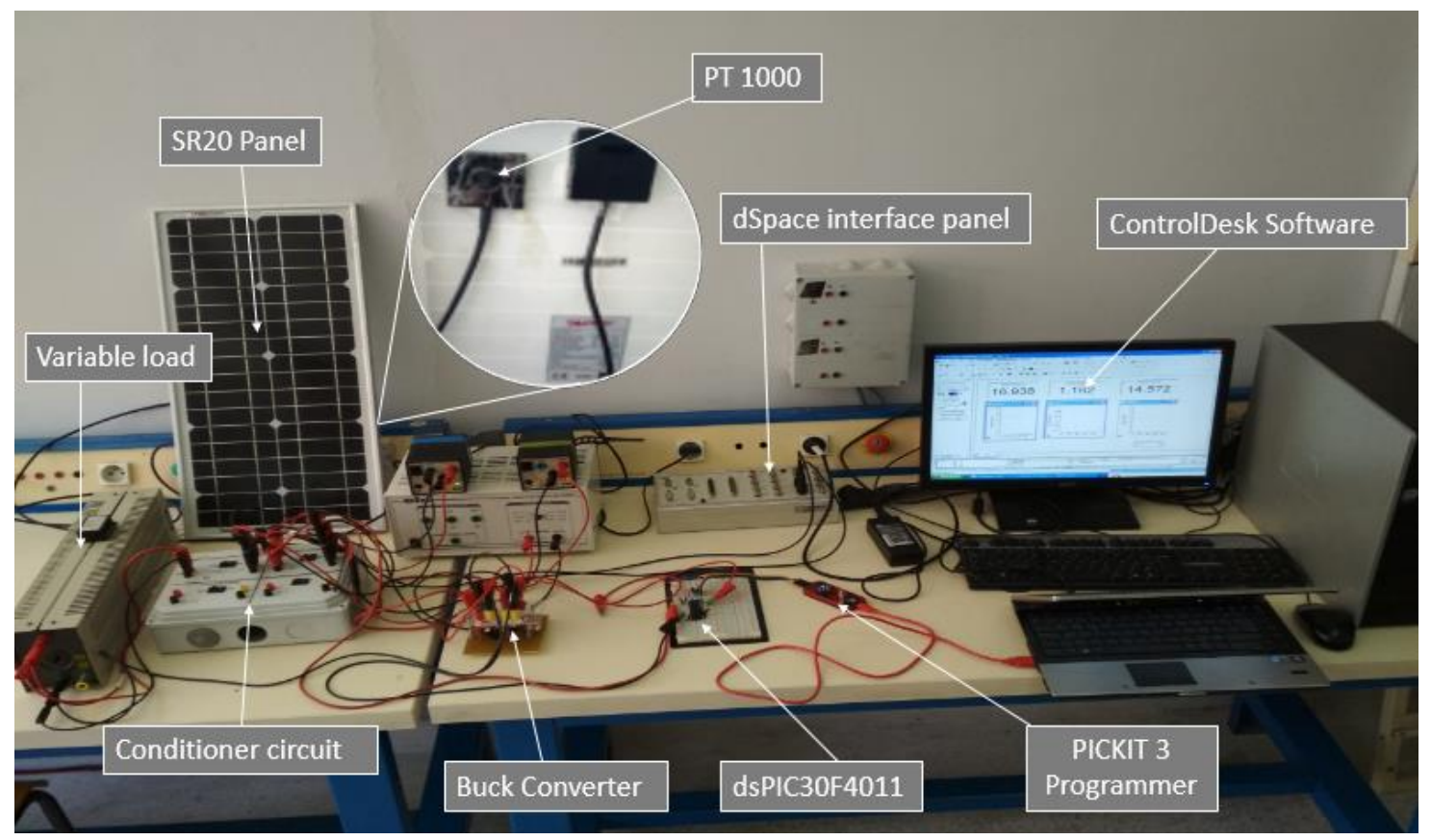

Figure 12. The key elements of the experimental setup 


\section{- Steady state validation}

The PV emulator steady-state was validated for given values of temperature and solar radiation. Figure 13 illustrates the comparison between the I-V characteristics obtained from the adjusted model and those obtained from the developed prototype. Two cases were considered $\left(\mathrm{G}=1000 \mathrm{~W} / \mathrm{m}^{2}, \mathrm{~T}=25^{\circ} \mathrm{C}\right)$ and $(\mathrm{G}=800$ $\left.\mathrm{W} / \mathrm{m}^{2}, \mathrm{~T}=25^{\circ} \mathrm{C}\right)$. The current-voltage characteristics acquisition is performed using a variable load $(0-25$ $\Omega$ ). As can be seen in Figure 13(a), the developed emulator can reproduce the same electrical I-V characteristic as the $\mathrm{PV}$ model, in this case, $\mathrm{G}=1000 \mathrm{~W} / \mathrm{m}^{2}$ and $\mathrm{T}=25^{\circ} \mathrm{C}$, which corresponds to the Standard Test Conditions (STC) indicated in the datasheet. The designed $\mathrm{PV}$ emulator has reproduced $\mathrm{V}_{\mathrm{MP}}=17.2 \mathrm{~V}$, $\mathrm{I}_{\mathrm{MP}}=1.17 \mathrm{~A}, \mathrm{I}_{\mathrm{SC}}=1.28 \mathrm{~A}, \mathrm{~V}_{\mathrm{OC}}=21.6 \mathrm{~V}$ given in the datasheet as the PV model. Figure 13(b) illustrates the comparison between the electrical behavior of the PV model and the developed prototype for $\left(\mathrm{G}=800 \mathrm{~W} / \mathrm{m}^{2}\right.$, $\mathrm{T}=25^{\circ} \mathrm{C}$ ), it observed that the model and the PV emulator behaves similarly as the emulated PV panel. The errors occurred are due to the sensor's uncertainty and the errors related to the ADC, such as the I/O pin crosstalk and the EMI induced noise. Finally, the steady-state behavior of the developed emulator agrees with the PV panel behavior.
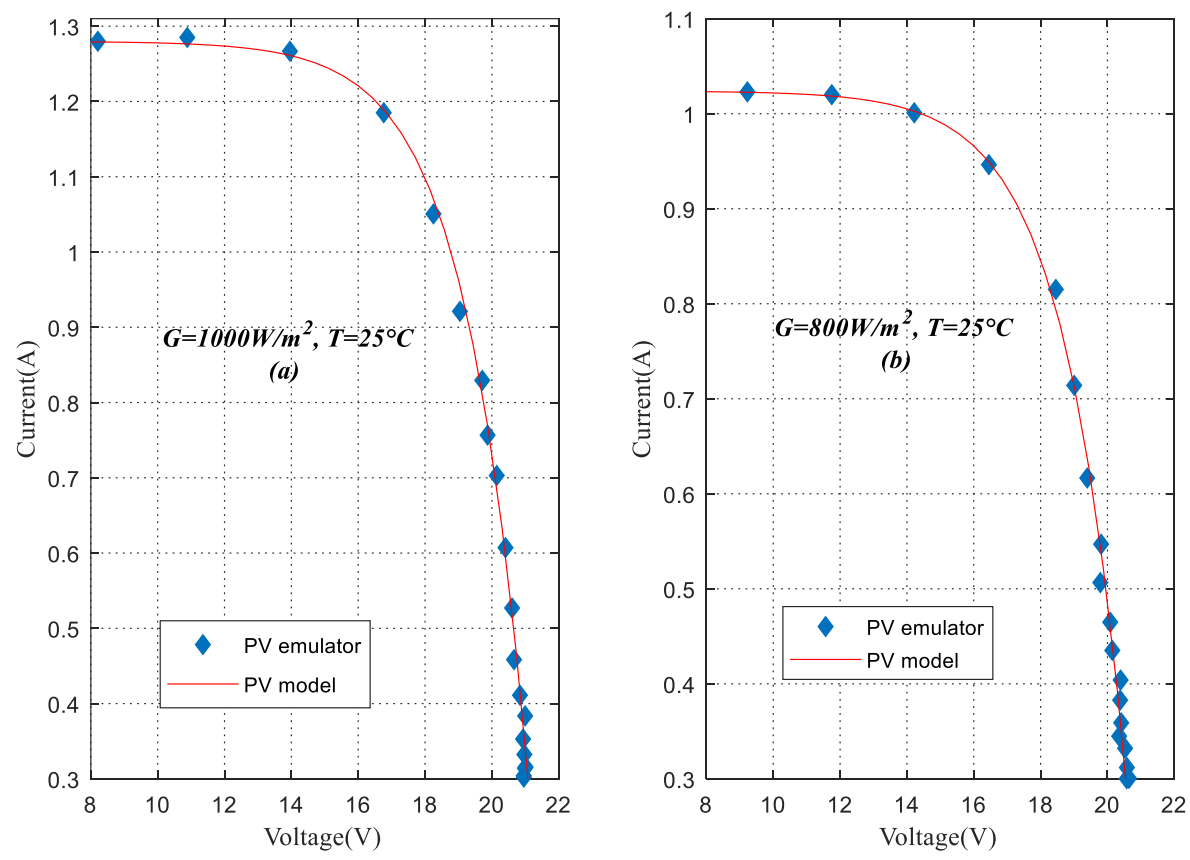

Figure 13. Steady state validation

\section{- Dynamic state validation}

The dynamic performances of the emulator were validated for transient variations of load, solar radiation, and temperature. Figure 14 illustrates the tests related to solar radiation and temperature. During the transient test of solar radiation, the PV emulator was connected to a given load $(15 \Omega)$, and the temperature value was equal to $25^{\circ} \mathrm{C}$. The solar radiation was initially equal to $1000 \mathrm{~W} / \mathrm{m}^{2}$ (STC conditions), the load connected is almost equal to the optimal load $\left(\mathrm{V}_{\mathrm{MP}} / \mathrm{I}_{\mathrm{MP}}=14.7 \mathrm{Ohm}\right)$, the obtained values are $\mathrm{P}=\mathrm{P}_{\mathrm{MP}}=20 \mathrm{~W}$, $\mathrm{I}_{\mathrm{PVE}}=\mathrm{I}_{\mathrm{MP}}=1.17 \mathrm{~A}, \mathrm{~V}_{\mathrm{PVE}}=\mathrm{V}_{\mathrm{MP}}=17.2 \mathrm{~V}$.

At the instant $\mathrm{t}=5.5 \mathrm{~s}$, the solar radiation suddenly passed from $1000 \mathrm{~W} / \mathrm{m}^{2}$ to $800 \mathrm{~W} / \mathrm{m}^{2}$, the current and the output voltage decreased considerably, the output power dropped by $5 \mathrm{~W}$. we conclude that the designed emulator correctly tracks the transient variations of solar radiation. It is also confirmed that the performances of the photovoltaic panels are significantly dependent on solar irradiation. The same for transient temperature variations, the temperature was initially fixed at $35^{\circ} \mathrm{C}$ and then suddenly decreased to $25^{\circ} \mathrm{C}$. It is observed in Figure 14 that the output power increases in agreement with the SR-20 panel dynamic behaviour. 

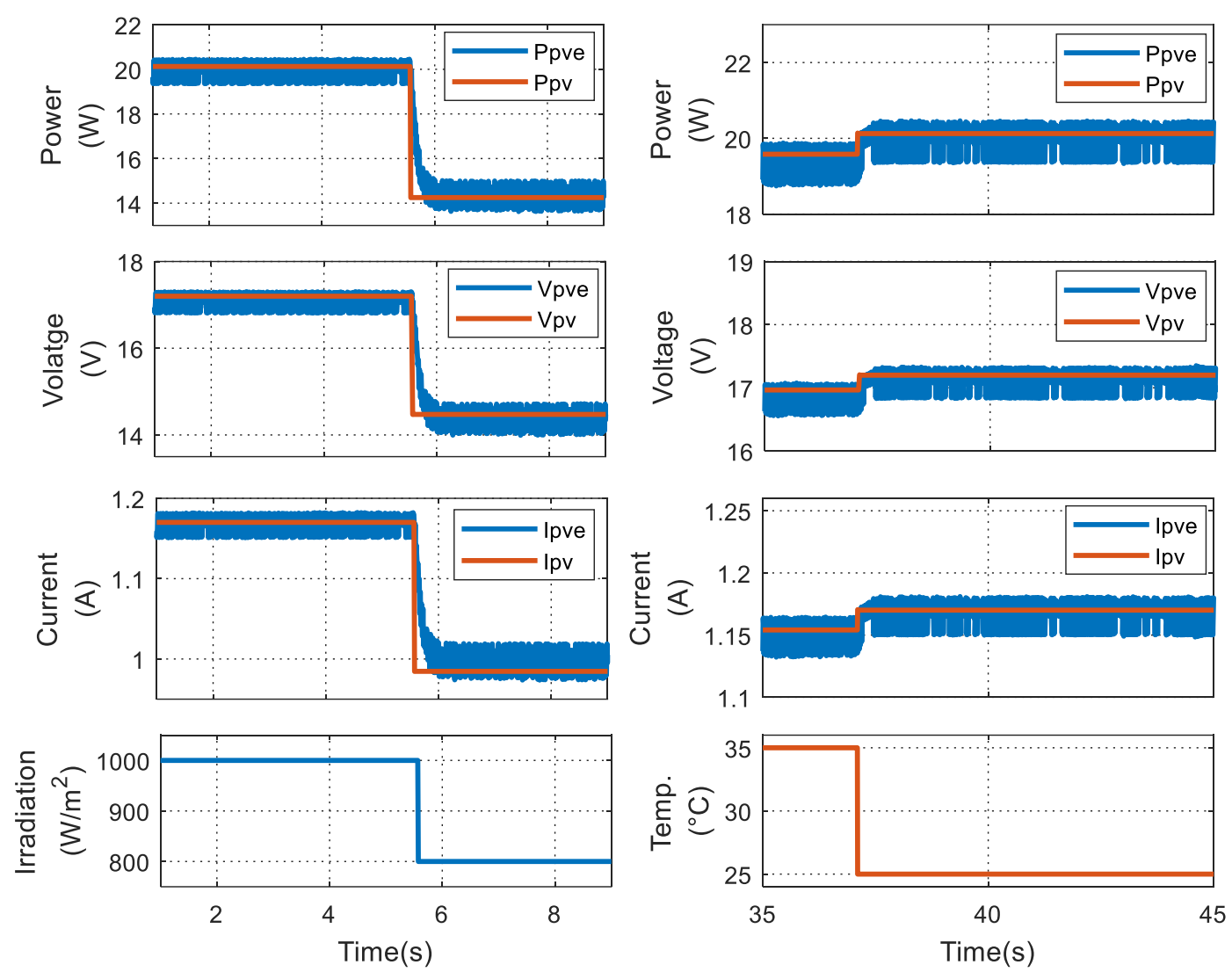

Figure 14. Photovoltaic emulator performance analysis under transient variations of solar radiation $\left(1000 \mathrm{~W} / \mathrm{m}^{2}\right.$ to $\left.800 \mathrm{~W} / \mathrm{m}^{2}\right)$ and temperature $\left(35^{\circ} \mathrm{C}\right.$ to $\left.25^{\circ} \mathrm{C}\right)$

The proposed emulator was subjected to transient variations of the load. The solar radiation and the temperature were fixed during this test. Three load values were used. The transition from one load value to another is carried out suddenly by the controlled relays. The results of this experiment are illustrated in Figure 15. in the interval [22s, 31s], a load of $7 \mathrm{Ohm}$ is connected. This test scenario is close to shortcircuiting condition, the current $\mathrm{I}_{\mathrm{PVE}}=\mathrm{I}_{\mathrm{SC}}=1.28 \mathrm{~A}$. In the interval $[13 \mathrm{~s}, 22 \mathrm{~s}]$ and $[31,40]$, a load of $15 \mathrm{Ohm}$ is connected, this condition is close to optimal operation $\left(\mathrm{V}_{\mathrm{MP}} / \mathrm{I}_{\mathrm{MP}}=14.7 \mathrm{Ohm}\right)$. The current $\mathrm{I}_{\mathrm{PVE}}=\mathrm{I}_{\mathrm{MP}}$ and the voltage $\mathrm{V}_{\mathrm{PVE}}=\mathrm{V}_{\mathrm{MP}}$. In the interval [5s, 13s] and [40,45] a $28 \mathrm{Ohm}$ load is connected, this test scenario is close to the open-circuit condition. The output voltage $\mathrm{V}_{\mathrm{PVE}}=\mathrm{V}_{\mathrm{OC}}$. Finally, it is concluded that the designed photovoltaic emulator tracks correctly the sudden variations in the load. The obtained currents and voltages respect the electrical behavior of the emulated panel. 


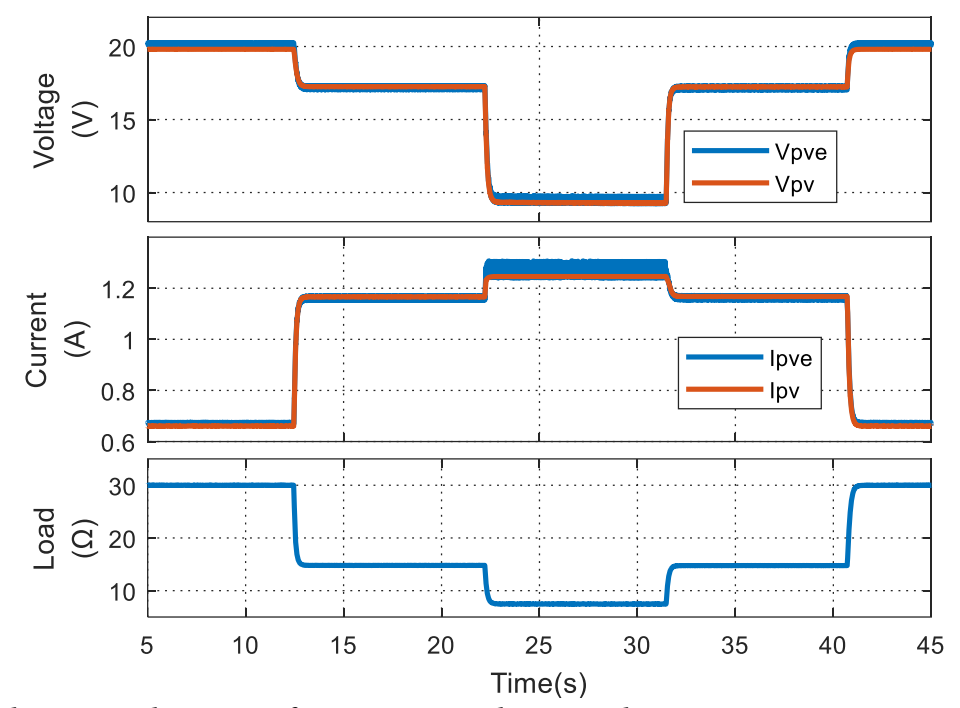

Figure 15. Photovoltaic emulator performance analysis under transient variations of load $(7 \Omega, 15 \Omega, 28$

$\Omega)$

\section{- Comparison with the existing PV emulators}

The proposed photovoltaic emulator is compared with three other existing PV emulators $[7,8,10]$. The comparison was conducted in two parts, the hardware and the software, as can be seen in Table 3. All emulators used a DC source with a Buck converter in the hardware part, but as a digital controller, the proposed emulator employs a dsPIC which is inexpensive compared to DSP, FPGA, and dSPACE. For PV panel modeling, the proposed work and the PV emulators in [7,8] adopt a single diode model, whereas a double diode model is used in [10]. The double diode is slightly accurate, but more complex than the single diode model. The implementation of the PV model was performed using a direct calculation method in $[7,8,10]$, since they are employing expensive (compared to dsPIC) digital controllers (DSP, dSPACE, FPGA), to resolve this problem a lookup table method was employed in this manuscript, which allows to use low-cost digital controllers with limited calculation capabilities. The commonly and easiest reference generation is the direct referencing method which is used in $[8,10]$, but it is not recommended as it generates oscillations at the emulator output [6]. The resistance comparison method proposed in [7], is more complex than the adopted $\mathrm{P} \& \mathrm{O}$ method as it needs load resistance measurement. The adaptive PI controller is more optimized than the proposed controllers in $[7,8,10]$. MPLAB X IDE is free of cost while buying a MATLAB/Simulink license will considerably increase the development cost of the emulator, as done in $[7,8,10]$. Finally, we can conclude that the proposed emulator is offering a low-cost architecture, that can be used in laboratories with limited budget, but not at the expense of performances as confirmed by the previous experimental results.

Table 3. Comparison of the proposed emulator with the existing emulators

\begin{tabular}{|c|c|c|c|c|c|c|}
\hline \multirow[b]{2}{*}{ Ref. } & \multirow[b]{2}{*}{ Hardware part } & \multicolumn{5}{|c|}{ Software part } \\
\hline & & $\begin{array}{l}\mathrm{PV} \\
\text { model }\end{array}$ & $\begin{array}{l}\text { PV model } \\
\text { implmentation }\end{array}$ & $\begin{array}{l}\text { Reference } \\
\text { generation }\end{array}$ & $\begin{array}{l}\text { Feedback } \\
\text { control }\end{array}$ & $\begin{array}{l}\text { Programming } \\
\text { software }\end{array}$ \\
\hline $\begin{array}{l}\text { This } \\
\text { study }\end{array}$ & $\begin{array}{l}\text {-DC source } \\
\text {-Buck Converter } \\
\text {-dsPIC }\end{array}$ & 1D2R & $\begin{array}{l}\text { Lookup Table } \\
\text { approach }\end{array}$ & $\mathrm{P} \& \mathrm{O}$ & $\begin{array}{l}\text { Adaptive } \\
\text { PI }\end{array}$ & $\begin{array}{l}\text { MPLAB X } \\
\text { IDE }\end{array}$ \\
\hline [7] & $\begin{array}{l}\text {-DC source } \\
\text {-Buck Converter } \\
\text {-DSP }\end{array}$ & 1D2R & $\begin{array}{l}\text { Direct } \\
\text { Calculation }\end{array}$ & $\begin{array}{l}\text { Resistance } \\
\text { comparison }\end{array}$ & $\begin{array}{l}\text { Hysteresis } \\
\text { controller }\end{array}$ & Matlab/Simulink \\
\hline [8] & $\begin{array}{l}\text {-DC source } \\
\text {-Buck Converter } \\
\text {-dSPACE board }\end{array}$ & 1D2R & $\begin{array}{l}\text { Direct } \\
\text { Calculation }\end{array}$ & $\begin{array}{l}\text { Direct } \\
\text { referencing }\end{array}$ & $\begin{array}{l}\text { PI } \\
\text { controller }\end{array}$ & Matlab/Simulink \\
\hline
\end{tabular}




\begin{tabular}{|l|l|l|l|l|l|l|}
\hline$[10]$ & $\begin{array}{l}\text {-DC source } \\
\text {-Buck Converter } \\
\text {-FPGA }\end{array}$ & 2D2R & $\begin{array}{l}\text { Direct } \\
\text { Calculation }\end{array}$ & $\begin{array}{l}\text { Direct } \\
\text { referencing }\end{array}$ & $\begin{array}{l}\text { PI } \\
\text { controller }\end{array}$ & Matlab/Simulink \\
\hline
\end{tabular}

\section{CONCLUSION}

In this paper, a simple and efficient PVE design and implementation has been proposed. The hardware design equations are presented to facilitate its implementation on a dsPIC device or any similar digital platforms. The developed porotype is efficient and straightforward, and it is running at a maximum speed of 30 MIPS (Million Instruction Per Second).

The PV emulator accuracy depends on the PV model and the controller design. For this reason, the PV model was validated in real weather conditions and compared with the actual PV panel, instead of referring to datasheet curves. The closed-loop control is based on an adaptive PI controller, and a P\&O algorithm was adopted for reference generation. This innovative technique is easily implementable on any digital platform. The cost of the developed prototype is about 150 USD which make it low- cost compared with commercial PV emulators (6385 USD to 21,000 USD), but note at the expense of accuracy and simplicity. The proposed method was experimentally validated under different operating conditions, of load, temperature and solar radiation. The results show that the developed emulator operates correctly as the emulated solar panel SR-20, in both transient and steady states.

The developed prototype can be used for educational purpose or by companies operating in the field of solar energy to perform their tests regardless of climatic conditions, especially in countries with a short period of sunshine. The prototype developed is still not perfect, hardware improvements are being made, making the prototype more accurate, by reducing the errors coming from sensors, electrical wiring. An HMI (Human Machine Interface) is also necessary to control the emulator externally, instead of making changes at the program level.

\section{CONFLICTS OF INTEREST}

No conflict of interest was declared by the authors.

\section{REFERENCES}

[1] Ram, J.P., Manghani, H., Pillai, D.S., Babu, T.S., Miyatake, M., Rajasekar, N., “Analysis on solar PV emulators: A review", Renewable and Sustainable Energy Reviews, 81:149-160, (2018).

[2] Armstrong S., Lee, C.K., Hurley, W.G., "Investigation of the harmonic response of a PVsystem with a solar emulator", 2005 European Conference on Power Electronics and Applications, Dresde, Germany, (2005).

[3] Nagayoshi, H., "I-V curve simulation by multi-module simulator using I-V magnifier circuit", Solar Energy Materials and Solar Cells, 82: 159-167, (2004).

[4] Moussa, I., Khedher, A., Bouallegue, A., "Design of a Low-Cost PV Emulator Applied for PVECS", Electronics, 8(2): 232, (2019).

[5] Schofield, D.M.K., Foster, M.P., Stone, D.A., "Low-cost solar emulator for evaluation of maximum power point tracking methods", Electronics Letters, 47(3): 208-209, (2011).

[6] Ayop, R., Tan, C.W., "A comprehensive review on PVE”, Renewable and Sustainable Energy Reviews, 80: 430-452, (2017). 
[7] Rana, A.V., Patel, H.H., "Current controlled buck converter based PVE”, Journal of Industrial and Intelligent Information, 1(2): 91-96, (2013).

[8] Azharuddin,S.M.,Vysakh, M.,Thakur, H.V., Nishant,B., Babu,T.S., Muralidhar,K., Paul,D., Jacob,B., Balasubramanian,K., Rajasekar,N., "A near accurate solar PV emulator using dSPACE controller for real-time control”, Energy Procedia, 61: 2640-2648, (2014).

[9] Balato, M., Costanzo, L., Gallo, D., Landi, C., Luiso, M. ,Vitelli, M., "Design and implementation of a dynamic FPAA based PVE", Solar Energy, 123: 102-115, (2016).

[10] Moussa, I., Khedher, A., "PVE based on PV simulator RT implementation using XSG tools for an FPGA control: Theory and experimentation", International Transactions on Electrical Energy Systems, 9(8), (2019).

[11] Villalva, M.G., Gazoli, J.R., Ruppert Filho, E.,"Comprehensive approach to modeling and simulation of PVarrays", IEEE Transactions on Power Electronics, 24(5): 1198-1208, (2009).

[12] Kumar, R., Singh, S.K. "'Solar photovoltaic modeling and simulation: As a renewable energy solution”, Energy Reports, 4: 701-712, (2018).

[13] Temli, S., Dincer, F., "Modeling of photovoltaic panel and examining effects of temperature in Matlab/Simulink", Elektronika ir Elektrotechnika, 109: 35-40, (2011).

[14] Ayop, R., Tan, C.W., "A comparison study of interpolation and circuit based PVmathematical models", 2016 IEEE International Conference on Power and Energy (PECon), Malaysia, 626631, (2016).

[15] Mallal, Y., El Bahir, L., Hassboun, T., "High-Performance Emulator for Fixed Photovoltaic Panels", International Journal of Photoenergy, (2019).

[16] Gonzalez-Llorente, J., Rambal-Vecino, A., Garcia-Rodriguez, L.A., Balda, J.C., Ortiz-Rivera , E.I., "Simple and efficient low power photovoltaic emulator for evaluation of power conditioning systems", 2016 IEEE Applied Power Electronics Conference and Exposition (APEC), California, 3712-3716, (2016).

[17] Can, H., "Model of a photovoltaic panel emulator in MATLAB-Simulink", Turkish Journal of Electrical Engineering \& Computer Sciences, 21(2): 300-308, (2013).

[18] Koran, A.M., "PV source simulators for solar power conditioning systems: design optimization, modeling, and control”, PhD. Thesis, Virginia Tech, Virginia, 17-35, (2013).

[19] Internet: dsPIC30F Family Reference Manual, in Microchip website. http://ww1.microchip.com/downloads/en/DeviceDoc/70046e.pdf, (2019).

[20] Internet: dsPIC30F/33F Programmer's Reference Manual, in Microchip website. http://ww1.microchip.com/downloads/en/devicedoc/70157b.pdf, (2019). 